\title{
EEG slow-wave mediates the fragmentation and coupling of cortical networks in propofol-induced general anesthesia
}

\author{
Kaier Wang ${ }^{1}$, Moira L Steyn-Ross ${ }^{1}$, Alistair Steyn-Ross ${ }^{1 *}$, Marcus T Wilson ${ }^{1}$, Jamie W Sleigh ${ }^{2}$ \\ From 24th Annual Computational Neuroscience Meeting: CNS*2015 \\ Prague, Czech Republic. 18-23 July 2015
}

Electroencephalogram (EEG) recorded from propofolinduced general anesthesia is characterized by large amplitude slow-waves $(0.1-1.5 \mathrm{~Hz})$. Clinically, these lowest frequency components of the EEG signal become dominant over other higher frequency components during and after loss of consciousness [1]. However, it remains unclear how these slow oscillations are produced and to what extent they reflect changes in cortical

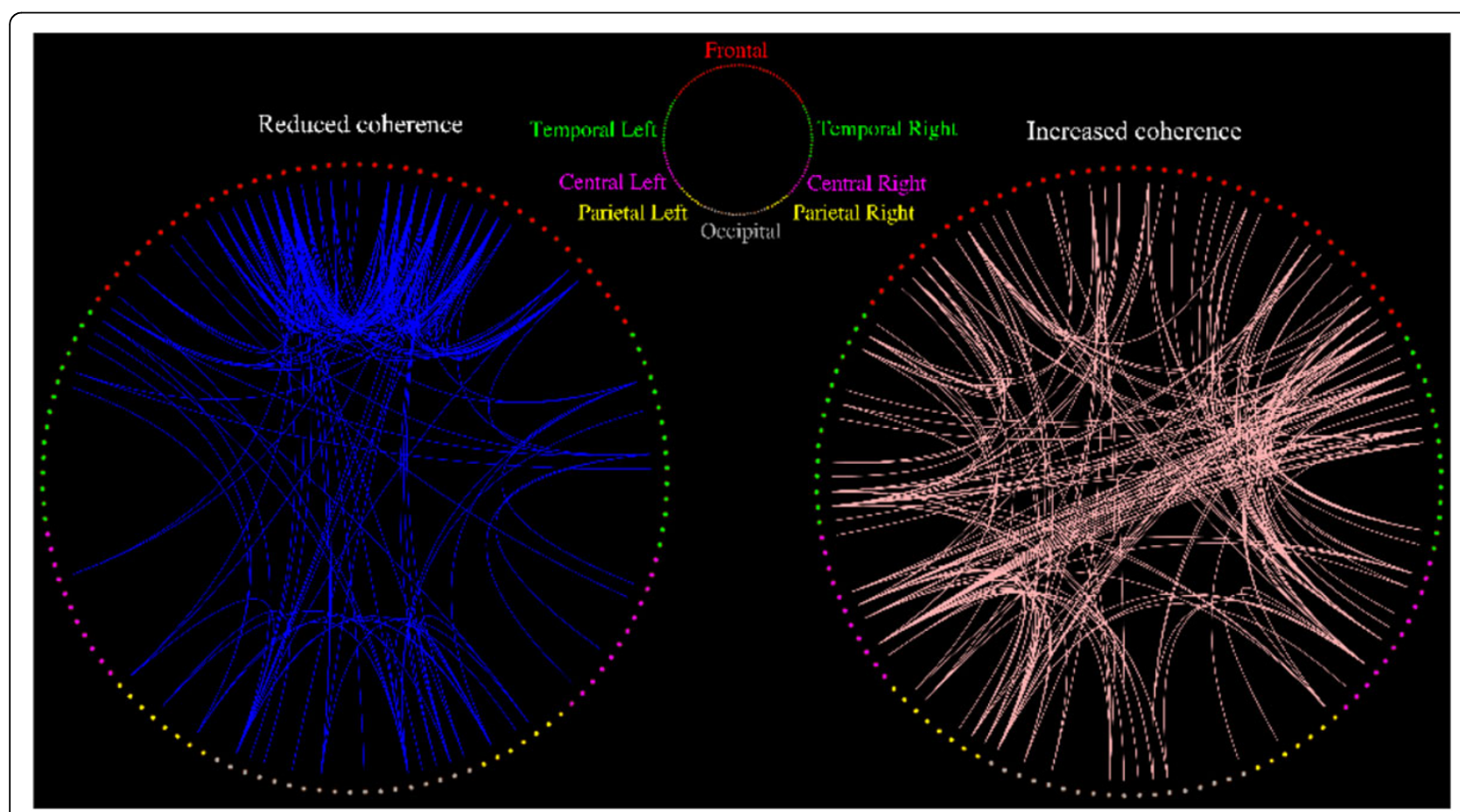

Figure 1 Correlation representations showing electrode pairs with significantly reduced (left, blue) or increased (right, pink) phasecoherence for sub-delta band $\mathbf{( 0 . 0 5 - 1 . 5 ~ H z ) ~ E E G ~ i n d u c e d ~ b y ~ p r o p o f o l ~ a n e s t h e s i a . ~ O n l y ~ e l e c t r o d e ~ p a i r s ~ ( f r o m ~} 128$ scalp electrodes) showing significant $(p<0.025)$ change in phase coherence are connected with lines.

\footnotetext{
* Correspondence: asr@waikato.ac.nz

'School of Engineering, The University of Waikato, Hamilton, 3240, New

Zealand

Full list of author information is available at the end of the article
} original work is properly cited. The Creative Commons Public Domain Dedication waiver (http://creativecommons.org/publicdomain/ zero/1.0/) applies to the data made available in this article, unless otherwise stated. 
network connectivity. Modeling anesthesia as a moderate reduction in interneuronal gap-junction coupling, a recent theoretical work by Steyn-Ross et al [2] predicts emergence of anesthetic slow-waves with chaotic dynamics. In the modeled anesthesia state, the weakened gap-junction coupling supports a codimension-2 bifurcation point where competing Turing (space) and Hopf (time) dynamics coexist, signifying spontaneous symmetry-breaking instabilities in the firing behavior of cortical neurons. Further, these chaotic slow-waves are found to perturb the neuronal coupling across the cortex, leading to a dramatic drop in global phase-coherence compared to its high level during consciousness. In this study, we analyze clinically-recorded EEG data to examine the model prediction for changes in phase-coherence between pairs of EEG channels in the sub-delta band during propofol anesthetic induction. Our study finds a coherence decrease in the frontal and occipital regions (see left panel of Figure 1), as well in the connection between them. Concomitantly, more strongly coupled neuronal activities are disclosed in the temporal-frontal, temporal-occipital and left-right temporal regions (right panel). Our clinical observation of reduced EEG coherence is consonant with cortical model predictions. However, our EEG study indicates that the coherence alternation is regional in nature, while the cortical model describes a spatially-uniform trend. Moreover, we did not find any theoretical prediction for the left- and right-temporal increased-coherence patterns. As the cortical model by Steyn-Ross et al. is spatially homogenous, i.e., there are no explicit front-to-back or right-to-left directionality, it is unable to produce regional coherence changes. It appears that the Steyn-Ross cortical model best represents the cortical dynamics in the frontal region.

\section{Authors' details}

${ }^{1}$ School of Engineering, The University of Waikato, Hamilton, 3240, New Zealand. ${ }^{2}$ Waikato Clinical School, The University of Auckland, Waikato Hospital, Hamilton, 3240, New Zealand.

Published: 18 December 2015

\section{References}

1. Lewis LD, Weiner VS, Mukamel EA, Donoghue JA, Eskandar EN, Madsen JR, et al: Rapid fragmentation of neuronal networks at the onset of propofol-induced unconsciousness. Proc. Natl. Acad. Sci. U.S.A 2012, 109: E3377-E3386.

2. Steyn-Ross ML, Steyn-Ross DA, Sleigh JW: Interacting Turing-Hopf instabilities drive symmetry-breaking transitions in a mean-field model of the cortex: a mechanism for the slow oscillation. Phys. Rev. X 2013, 3:021005.

doi:10.1186/1471-2202-16-S1-P231

Cite this article as: Wang et al: EEG slow-wave mediates the fragmentation and coupling of cortical networks in propofol-induced general anesthesia. BMC Neuroscience 2015 16(Suppl 1):P231.

\section{Submit your next manuscript to BioMed Central and take full advantage of:}

- Convenient online submission

- Thorough peer review

- No space constraints or color figure charges

- Immediate publication on acceptance

- Inclusion in PubMed, CAS, Scopus and Google Scholar

- Research which is freely available for redistribution 